\title{
An Implementation Model of Teaching Evaluation Questionnaire System Based on Cloud Computing
}

\author{
Chih-Yung Chen ${ }^{1}$ and Jih-Fu Tu ${ }^{2}$ \\ ${ }^{1}$ Department of Information Management, St. John's University, 499 Section 4, Tam King Road, \\ Tamsui District, New Taipei City 25135, Taiwan \\ ${ }^{2}$ Department of Electronic Engineering, St. John's University, 499 Section 4, Tam King Road, \\ Tamsui District, New Taipei City 25135, Taiwan \\ Correspondence should be addressed to Chih-Yung Chen; yung@mail.sju.edu.tw
}

Received 29 June 2014; Accepted 27 August 2014; Published 25 September 2014

Academic Editor: Stephen D. Prior

Copyright (C) 2014 C.-Y. Chen and J.-F. Tu. This is an open access article distributed under the Creative Commons Attribution License, which permits unrestricted use, distribution, and reproduction in any medium, provided the original work is properly cited.

\begin{abstract}
The teaching evaluation questionnaire in the university has been an essential routine. The administrative staff of academic affairs shall obey the rules, fairness, and valid principles within the period of finishing teaching evaluation questionnaire. To ensure the accuracy and timeliness of the large number of questionnaires, it makes the administrative staff of academic affairs face the challenge and pressure if the students are too many. Program potency low or bad often came from the development staff being familiar with bad program development idea; the bad designs of system program in itself causes the factor proportion to occupy more higher, because the similar application program mode of writing is, respectively, different. However, the exploiter may find the method of the little consumption of system resources to complete the similar work task. We develop the software service of cloud platform and the educational administration personnel operates process in the software service of cloud platform. The cloud platform reduces the system wait and calculation time of questionnaire, improves and simplifies system operation flow, and promotes 10 times of program efficiencies as well as solving the load overweight problem of potency bottleneck.
\end{abstract}

\section{Introduction}

This research is taken with various differently angle ponder appraisals by the system user, demand, and exploiter and establishes the analysis and discussion according to each demand and characteristic, to present the key consideration for the implementation of study teaching evaluation questionnaire system, and establishes the clouds platform system to implement the teaching evaluation questionnaire work, which appraises the result of implementation. Finally we propose the conclusion of this research for the future reference of school affairs administrative efficiency appraisal and promote the computerization of school affairs administration and establish the reference of school affairs special case for the commander institution of education unit, nonprofit organization $[1,2]$, and information manufacturer. In order to promote teacher teaching quantity and student study result in the school of this research, teaching quantity, good and bad of teaching quantity indirectly affects the student study result. According to the learning process of student with interest, ability, teachers, achievement, time coordination, and other factors considered, we pay great attention not only the request that has the fairness but also embrace the high expectation whether to help the promotion of teacher teaching quantity and student study result. Simultaneously we provide the teacher evaluation, selection of teaching fine and outstanding teacher, and others of the related evidence material and understand operations result and performance reviews for the commander institution of education unit and board of directors target $[1,3]$.

The teaching evaluation questionnaire has been important routine services in the national universities and colleges. The educational administration personnel must simultaneously give dual attention to the stipulation, fairness, and the valid principle and does the teaching evaluation questionnaire homework in the stipulating time interval. In 
order to guarantee the huge quantity questionnaire material with the accuracy and the instantaneity, the educational administration personnel are faced with the test and great pressure in the students scale over a thousand people or even over ten thousand people schools. Nowadays hardware source equipment which presents the explosive growth may carry on because of the CPU, memory, and storage hard disk related hardware device massively and operates $[4,5]$ fast and simultaneously has solved the operation and carries out the potency of the bottleneck and difficult position. When program operation meets the potency bottleneck or the load overweight issue, it may because of elastically expand the hardware source equipment to solve [6] continually, but this also grew hardware disbursement considerable substantial costs $[7,8]$.

This research evaluates the curriculum of at least 200 classes; the educational administration personnel want to transfer the teaching evaluation questionnaire by the information automatic treatment, avoiding causing the manual calculation mistake because of the excessive questionnaire quantity. However, the teaching evaluation questionnaire system links one of the original school affairs information system; the educational administration personnel react that the use of the system operation is not easy and its process is to be mistakable less than two school years, although it may recover and be corrected by the way of revision information database; however, its process has to lose the fairness and appraisal result is easy to be questioned; it reacts that the system load is heavy easily, and the waiting time of the calculation statistics of questionnaire is too long and the issues are numerous. Therefore, the educational administration personnel seek the information center engineer to take the gauge of the system condition whether it may make the improvement, hope to cut the error rate, and discuss the flow simplification work [9]. Simultaneously, this school information center also expressed that because the existing information system equipment is expensive and novel and its use is for less than three years, there is no consideration or plan to change school affairs information system hardware device in the short term. Therefore, this research takes revising the program to reduce the equipment capital outlay as the principle and explores the teaching evaluation questionnaire issue to have the possible factor and designs to conform to the audiences to accept the system [10].

This research's objectives are (1) solving educational administration personnel issue; (2) taking revising the program as the principle and effectively solving the system effectiveness problem; and (3) understanding program development way regarding potency affects. And it hopes that the conformity of clouds service and the process of program code edition control and system development flow make the development staff to be possible for effectively lifting system to deliver the quality and lift system potency and effectively reduce the outlay cost of equipment augmentation to understand choice in the future or the use of clouds service and system special case development that may face the reference of risk, challenge, and related technology issue.

\section{Materials and Methods}

2.1. Continual Conformity. To establish the job of completed test environment, it is needed to spend many manpower operations and may achieve the resources of hardware environmental equipment, but in the software special case of development process, it is limited to the resources of environmental equipment and limiting factor of manpower. The most software testing is distributes to many manpower operations [11]. Therefore, this research promotes the test environment establishment process and quality because of the clouds automated mechanism and application interface $[12,13]$.

When during software development team is performing at its own function condition, perhaps the system is unable to stabilize in the effective executing state. When must come to the end of the system development or in the almost completed stage, the system mode gradually tends to the steady state, there is likely occurred when the system is unable to conform the final integration phase. Therefore when the software special case execution and development process are longer, the program code that accumulates is also more complex and is huger; the conformity work becomes very difficult, regulatory risk is also bigger, carried on with its and other special cases to the final stage and finds the problem and might as well shift to an earlier time to carry out the systems integration work, when in the program code was renewed and revision, namely, carries on the automated conformity work. Therefore management master of continual conformity Martin Fowler proposes main conditions of the development pattern of continual conformity which are as follows:

(i) it manages independent program code;

(ii) it establishes the automation;

(iii) it establishes automated test;

(iv) the development staff may deliver to the main place to store up the program;

(v) the program code may establish on conformity machine;

(vi) it may establish fast;

(vii) it may duplicate the product environment to test;

(viii) it may make any development staff to obtain the most new program to carry out;

(ix) it may know the automated test result.

2.2. Program Code Edition Control. Program code edition control is the most important topic of software quality. Also it is the basis of development team and special case development. Before the end of program development life cycle, the system will continue along with the issue of system to occur with the improvement, the user demand change or the system environment change then grows various different issues; the system-related software and application program are inevitably also along with the system issue renewal or the edition correction, and in the system edition correction renewal process, it will cause it to carry out the edition forked 
working systematically and possibly extends various minutes of types of different branch editions along with the special case development demand. But the majority of enterprises are all impossible to establish the corresponding environment to the demand of application program system test situation completely. The test carries merely on the common simulation operation environment; even many small and mediumsized enterprises have not carried on to establish the test environment, or many small- and medium-sized enterprises that most often use the test environment are the product user immediately execution environments, but this situation regarding the program development quality without doubt is also a very big risk and cost, it possibly grows that there is not many to anticipate the situation.

\section{System Analysis and Design}

3.1. System Requirements. This objective of research is to the newly setup universities and colleges and it inducts the school affairs information system outward and contains the educational administration and student business, general affairs, accountant and special case project management, human affairs, and other major school affairs information systems. But the induction process in school affairs information system function has the urgent demand regarding some system functions; however, it wants to use the system of part of old version or obsoletes to stop using and maintenance, and simultaneously inducts the above system; it causes the user operating system inconvenience or it is unable to use the situation accommodatingly. Since the use of paper operating type of implementation teaching evaluation questionnaire is from 2010, because of implementation process being complicated, it must spend environmental protection in the massive paper print to be easy to have the anxiety; the calculation statistics questionnaire result must be confirmed repeatedly and avoids mistake also being probable to spend a huge amount of manpower. Since 2011 it inducts the teaching evaluation questionnaire system and starts to implement the online work, initial period. The student teaching evaluation questionnaire fills in the answering rate not to reach the effective threshold. In 2012 the educational administration personnel reacted that the teaching evaluation questionnaire system must use the interactive operation when the system operated the local end educational administration system and Web end teaching evaluation questionnaire, and using operation in the system is hard and flow complication is mistakable. This research under this environment and background, regarding the concept and spirit of teaching evaluation questionnaire system development, is as follows:

(1) educational administration personnel unified in Web end operation processing, stopped using the Local end educational administration system;

(2) it reduced system wait time;

(3) it improved and simplified system operation flow;

(4) it promoted teaching evaluation questionnaire filling rate.

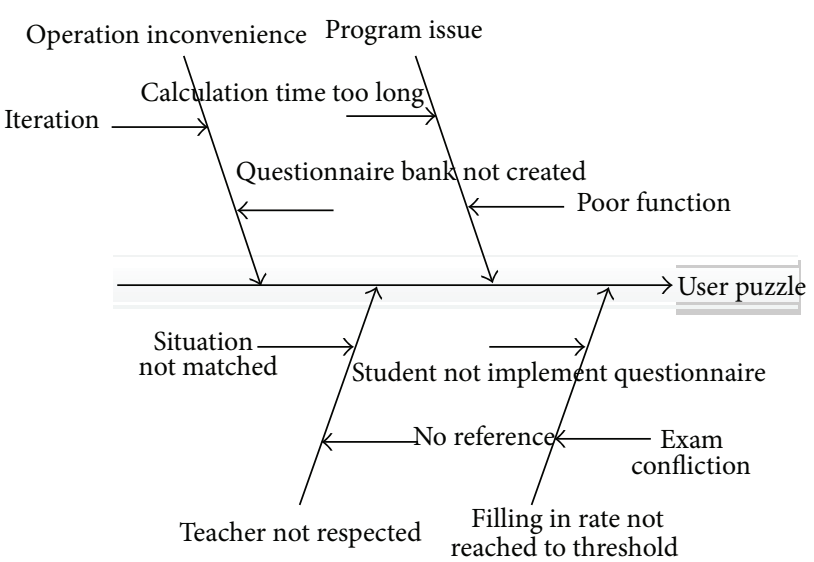

FIGURE 1: Teaching evaluation questionnaire system cause and effect.

In order to discover basic issue source, this research attempts to use Cause-and-Effect Diagram as shown in Figure 1 to look for and to reorganize the issue with the likely factors.

By Figure 1, we knew that the most subject matter is "user puzzles." But the line of subject matter links to indicate that it causes the subject matter of the possible essential factor: (1) operation inconvenience; (2) program issue; (3) the teacher not taking it seriously; and (4) filling rate not reaching the threshold. The line of possible essential factor links to indicate that it creates this essential factor of the possible detail factor. The issue induction originates for educational administration personnel and information center technical personnel reorganizes the issue.

(1) Operation Inconvenience. Whenever during carrying out the teaching evaluation questionnaire service, the educational administrative personnel responded due to the existing system operation process must unceasingly operate the teaching evaluation questionnaire system both from the local end of educational administration system and the web end of school affairs information system alternately. In addition, the system does not have the questionnaire database function in present; therefore, when establishing a questionnaire process needed to input redundant topic serial number, topic, option, format, and other changes manually every time, its operating process must truly record each system operation link and step and must truly carry out each link and step in order, may not jump over willfully, if some link misses or makes a mistake for which it will cause the entire teaching evaluation questionnaire system to be established with failure and incorrectness, and it must turn back to operate again. Also the present system does not have user interface to possibly intuit watching to the teaching evaluation questionnaire condition after establishing, it can only obtain the relevant record of teaching evaluation questionnaire from the database to judge abstractly, when carrying on the teaching evaluation questionnaire each time at least 200 curricula in the school,must establish at least 200 teaching evaluation questionnaires; there are at least 200 quantities $* 30$ (topic) $* 5$ (option) $* 3$ (format) approximately 90,000 records in the database; if only 
to establish simple effective teaching evaluation questionnaire we need tospend half workday time; afterward we must invite the administrative personnel in the unit and information center engineers to carry on the support to assist to carry on two times to check with the confirmation work, which result in the serious protracted administration program efficiency and manpower waste.

(2) Program Issue. After teaching evaluation questionnaire implementation had ended, when the educational administrative personnel wants to obtain the detailed teaching evaluation questionnaire statistical result among various curricula carries out the calculation program function; therefore the system must calculate at least 200 teaching evaluation questionnaires; its system calculation result time at least needs the time-consuming 30 minutes that may know and obtain the file after the settlement. Simultaneously the educational administrative personnel also responded that the existing teaching evaluation questionnaire system function is quite spring; operational procedure is also quite complicated, in establishing the teaching evaluation questionnaire or its operating process frequently presents the wrong program works to initiate as the machine goes down or the program has non-response picture; we suggested increasing development of various functions or the system edition corrections in order to lift system function to contain the degree of completeness and perfection.

(3) The Teacher Does Not Take Seriously. Some teachers think that the implementation of teaching evaluation questionnaire can come apart with the present condition and cannot have the reference value and proposed putting forward various dissident views warmly:

(i) the education is the conscience enterprise, subject to the teacher regards with that mentality; if the teacher will not care relatively, it will not have any coping style; instead it will be easy to become a mere formality;

(ii) the improvement with emphasis should use or assign human resources effectively properly in the teacher equipment and teaching assistant and other auxiliary means, but it is not only a service pattern of teaching evaluation questionnaire;

(iii) because the teaching and research were insufficient at the present time, we need more time patch, the arrangement of teaching material, such as spending the overtime in the teaching evaluation, causing this "time" to try to push each other out, which will not only help the teaching or the research;

(iv) if we implement the teaching evaluation questionnaire, because of its all sorts of factors, it can respond not necessarily objectively to the teaching evaluation result; it must have the teaching or study improvement of coordinated sets of measures, or it enhances the cause of the proportion but does not evaluate for the evaluation constantly;

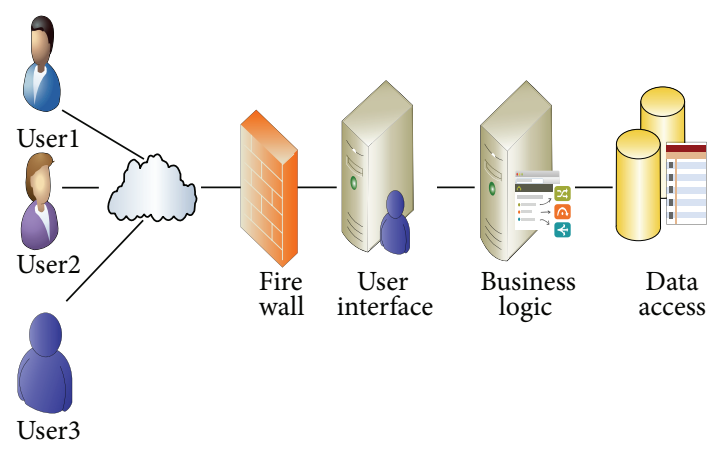

FIGURE 2: Three levels as the pattern framework of system development.

(v) for some open style issue, student opinions are not truly partially, but the teacher does not have the opportunity to communicate with these students to define clearly the misunderstanding;

(vi) the suggestion of filling in the teaching evaluation questionnaire is to be quite suitable again after the student graduates; the students do not not need to be worried to fail in course after the student graduates and do not not have individual stake; therefore in filling it is quite fair. Simultaneously after entering the society, the thought and behavior must be objective, fair, and mature; the students can understand the teaching way and intention of the teacher.

(4) Filling in Rate Has Not Reached Threshold. The embodiment of teaching evaluation questionnaire, because the student generally does not know what day to implement and does not clear to its goal and the importance of why implementation of teaching evaluation questionnaire, and lacks the cause of filling. During the implementation period of midterm and final term, compress the student to review the reviewing lessons time even there is student partially does not clear to the rule to think. If after filling in the negative opinion, the student will be got the result of low score by this curriculum teaching teacher. Therefore, few of the students even has not to be willing to fill in the teaching evaluation questionnaire, the common filling to answer of students for teaching evaluation questionnaire is less than $50 \%$ phenomena.

3.2. System Configuration. This research uses three levels as the pattern framework of system development as shown in Figure 2. The system is divided into three levels: showing user materials, the business logic, and material deposits and withdraws; each level is an independent system, and it has the dispersive, ductility, and cutting program of system function and easy maintenance. When some level of the hardware or the software must be promoted, replaced or broken down, it may by the parts of other correspondence levels of machine installment then immediately return to normal; it does not affect other level operations. But three levels may place the information database after the web server, making front 
program unable to be directly accessed, its material security and privacy are better than the client-server framework. (1) User Interface Layer: the web interface or the form for user interaction (to accept input, to demonstrate output) passes to the business logic layer the user movement and demonstrates the material of business logic layer transmission. (2) Business Logic Layer: as the bridge of the user interface and information database, it passes the input of user interface level to the data access layer and makes the business logic operation for the material of data access layer transmission and passes to the demonstration level again. (3) Data Access Layer: the information database deposit material or processing the information; it passes the material to the business logic layer.

3.3. System Implementation Model. This research uses C\# language to write program and uses Microsoft Visual Studio 2010 to translate and inducts clouds Team Foundation Service to take the program code edition control and conform with the server to establish and improve the development environment continually; the test environment is the Windows 7 Pro 32 bit operating systems, CPU is Intel Core2 Quad Q8300 CPU $2.5 \mathrm{GHz}$, and memory is $4 \mathrm{~GB}$ but may use the capacity is $3.5 \mathrm{~GB}$. The system changed the original teaching evaluation questionnaire system by the VB.Net language in the development process to $\mathrm{C} \#$ in order to conform to the information center to develop the centralized control language policy and analyzes the appraisal to the original teaching evaluation questionnaire system program code, in the unraveling process discovered that causes the system effectiveness with low dispirited and the factor of Cause-andEffect diagram Figure 1 of teaching of evaluation questionnaire system, this research reorganizes: first is because the system and database communication, and deposit is frequent, then it causes the system resources to consume and take excessively; second is in program execution operation process and must pass through insignificant condition judgment and flow and waiting and then causes the system resources to waste the waste; third is the functional variable use announced that amount of use oversized [14] or the frequent transformation attribute and attribute use improper, has not planned properly, and then causes the system resources to waste the waste; fourth has not established the program code edition control mechanism which is unable to know history and course that the program revises. And it is estimated that its overall development process is system analysis, design, test, online, and debugging the time interval and needs approximately three months of workday. When the system operation process entire facial suture of the clouds works, implementing the questionnaire needs the sole administrative manpower independently to complete the work task merely, and no longer needs to rely highly on other administrative personnel and information center development staff assists, to avoid the manpower waste, system operation sequence diagram as shown in Figure 3.

\section{Results and Discussion}

This research in this clouds work of system development on with the entire facial suture; the system function provided the parameters setting, the question bank design, and online questionnaire design and material inquiry, to draw lots to draw, and made the synthesis implementation to appraise to its subject matter $[10,15]$, such as Figure 4 establishing the questionnaire time needed comparison chart, according to the statistical result before the edition correction; it uses the system to establish 262 effective questionnaires to take the time-consuming 25747.96 seconds to be equal to 419.23 minutes is 7.15 hours, but it improves the flow to promote the system function to complement one another under the edition correction; it uses system to establish 262 effective questionnaires only to need time-consuming 1784.56 seconds to be equal to 29.74 minutes is 0.49 hour, the significance reduced for 6.66 hours. The operating time, simultaneously working efficiency significance, is promoted 16.98 times.

And it aims at the teaching evaluation questionnaire calculation statistics time to perform the overall assessment again, such as the Figure 5 questionnaire calculation time statistical result comparison chart, according to the statistical result before the edition correction; it uses the system to calculate 262 effective questionnaires to take the timeconsuming 3375.16 seconds to be equal to 56.25 minutes and is 0.93 hour but improves the flow and reduces unnecessary information database resources and system program resources under the edition correction consumed to complement one another; it uses system to calculate 262 effective questionnaires only to need time-consuming 319.46 seconds to be equal to 5.32 minutes and is 0.08 hour; the significance reduces 45.93 minutes of operating times; simultaneously the working efficiency significance is promoted 10.89 times.

The teaching evaluation questionnaire filling rate appraisal, such as Figure 6 questionnaire filling in rate statistical result comparison chart, according to the filling in rate of statistical result before the edition correction is $50.67 \%$, to the effective threshold $60 \%$ still disparities $9.33 \%$; it caused the threshold of the implementation not to be invalid; after the edition correction, the system prompts the student to fill in the questionnaire filling in rate to promote on own initiative is $99.37 \%$, it increases 1.96 times of filling in rates; the significance increases $48.70 \%$ than before the edition correction.

\section{Conclusion}

We learned from the system test and experimental result that the full effective solution comes across the bottleneck and issue, as shown in Figure 1 for the implementation teaching evaluation questionnaire of educational administrative personnel and took revising the program as the principle and understood when the program development way affects regarding the potency; implementing the teaching evaluation questionnaire needs the sole administrative manpower independently to complete the work task merely; its teaching evaluation questionnaire remarkable reduction setup time is 6.66 hours of operating time, simultaneously it obviously promotes working efficiency 16.98 times. Because of improvement database deposit and reduced unnecessary system resources consumption and improvement system calculation flow, it makes the calculation teaching evaluation 


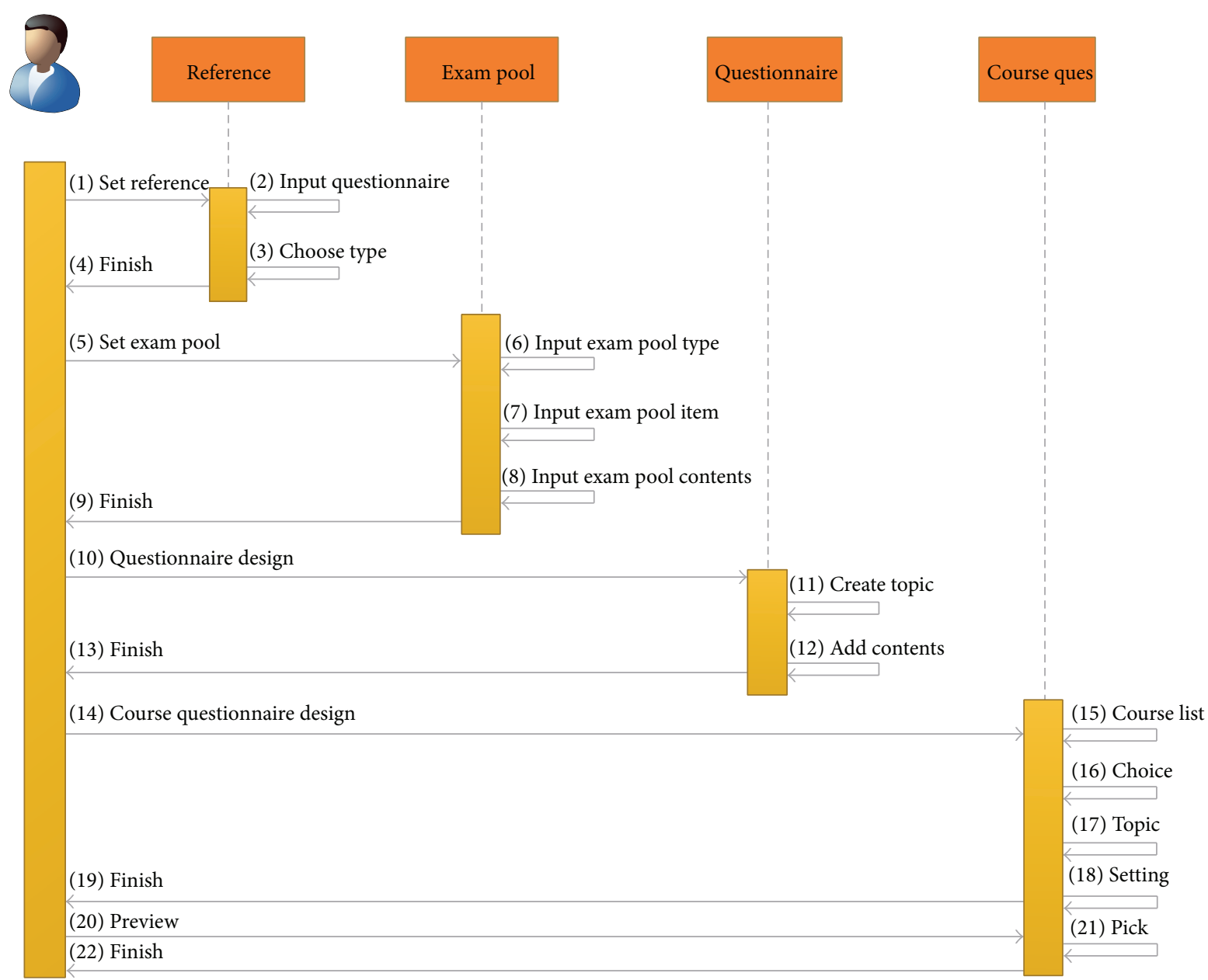

FIGURE 3: System operation sequence.

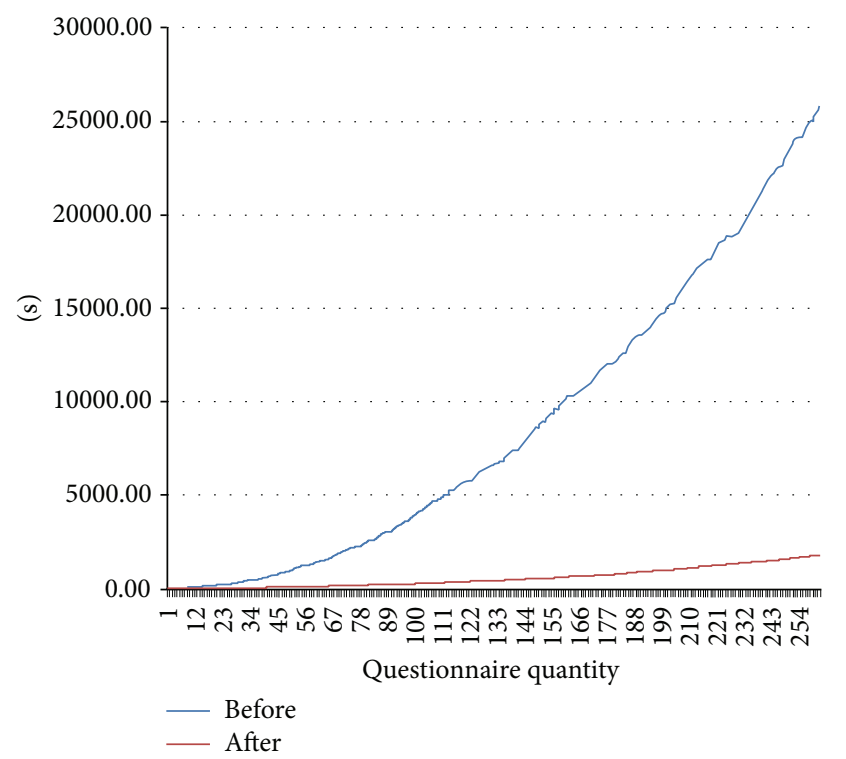

FIGURE 4: Established the questionnaire time needed comparison. questionnaire time significantly reduce 45.93 minutes of operating times; simultaneously it obviously promotes working efficiency 10.89 times, and effectively reduces increasingly the purchase hardware source equipment cost. And because of the improvement implementation teaching evaluation questionnaire module, to promote the teacher-student interaction to respond to the function effectively, the unimpeded communication channels have the good communication of teachers and students, to promote the relation of the teachers and students with each other, to achieve news exchange; we deeply understood that each teachers and students, making counsel to communicate among the teachers and students and promote the credibility effectively. But filled in the answering rate $50.69 \%$, it causes the implementation to be invalid because of not having the stipulations of $60 \%$ effective thresholds; now it is transferred by the system which informs the student to fill on his own initiative to answer the questionnaire and increases the cause of filling to answer for the student, making the student easier to be attracted, therefore filling in the answering rate drastically to promote to $99.37 \%$ to cross the effective threshold successfully; its research 


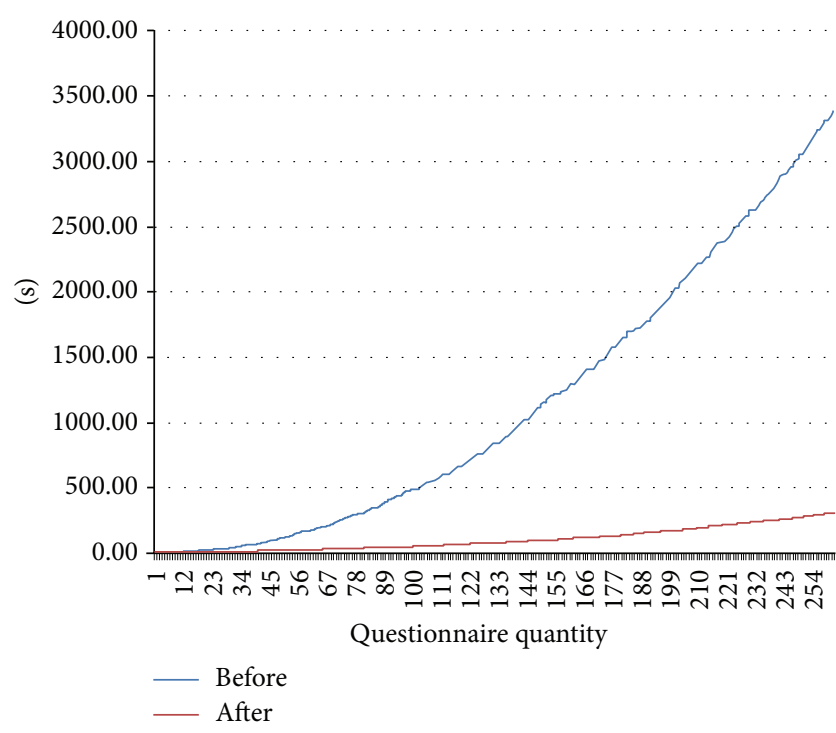

FIGURE 5: Questionnaire calculation time statistical result comparison.

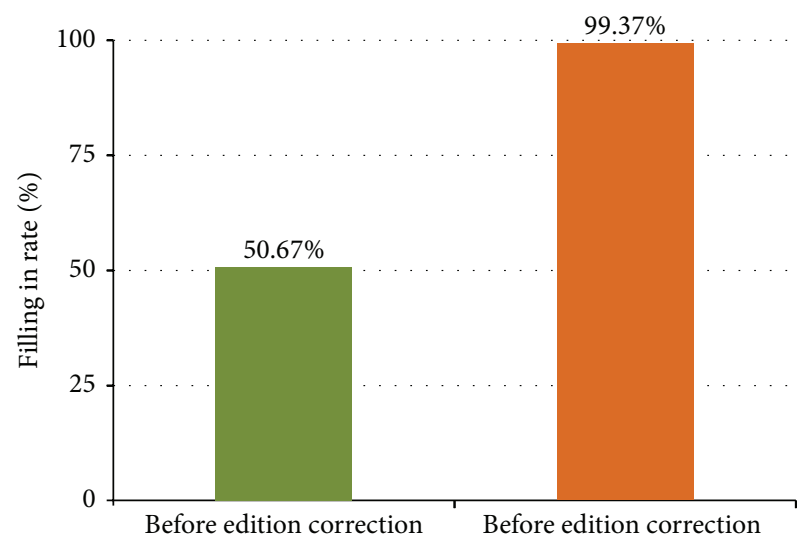

FIGURE 6: Questionnaire filling in rate statistical result comparison.

objective is all achieved. We use this research teaching evaluation questionnaire as an example; this implementing mode efficiency scale transformation, the information center engineer ability, and quality are establishing its technical feasibility key to be; the computerized degree often is regarded as one of the targets of the administrative efficiency and output value promotion, because of the information automatic treatment, besides it may save the manpower and funds disbursement; its method is both simple and effective and causes the teaching evaluation questionnaire to work effectively and with stable implementation.

\section{Conflict of Interests}

The authors declare that there is no conflict of interests regarding the publication of this paper.

\section{References}

[1] M. S. Wang, C. D. Chen, S. C. Chang, and Y. H. Yang, "Effects of online shopping attitudes, subjective norms and control beliefs on online shopping intentions: a test of the theory of planned behaviour," International Journal of Management, vol. 24, no. 2, pp. 296-302, 2007.

[2] US EPA, Report to Congress on Server and Data Center Energy Efficiency Public Law. Report to Congress, U.S. Environmental Protection Agency, 2007.

[3] C. Yang, "The cloud computing technical guidelines," Okahata asset management, 2010.

[4] Y. Chu and A. Ganz, "A mobile teletrauma system using 3G networks," IEEE Transactions on Information Technology in Biomedicine, vol. 8, no. 4, pp. 456-462, 2004.

[5] D. G. Gregg, Y. Wan, and J. Yao, "A web services-based distributed system with browser-client architecture to promote tele-audiology assessment," Telemedicine and e-Health, vol. 15, no. 8, pp. 413-447, 2009.

[6] B. Ohlman, A. Eriksson, and R. Rembarz, "What networking of information can do for cloud computing," in Proceedings of the 18th IEEE International Workshops on Enabling Technologies: Infrastructures for Collaborative Enterprises (WETICE '09), pp. 78-83, Groningen, The Netherlands, July 2009.

[7] D. J. Brown and C. Reams, "Toward energy-efficient computing," Communications of the ACM, vol. 53, no. 3, pp. 50-58, 2010.

[8] W. D. Deng, The Clouds Computing Have a Bowel Movement Secret, The BP social publications, Taipei, China, 2010.

[9] M. Armbrust, A. Fox, R. Griffith et al., Above the clouds: a berkeley view of cloud computing, 2009.

[10] Introduction to Cloud Computing Architecture, Sun Microsystems, 1st edition, 2009.

[11] A. G. Malishevsky, G. Rothermel, and S. Elbaum, "Modeling the cost-benefitstradeoffs for regression testing techniques," in Proceedings of the International Conference on Software Maintenance, pp. 230-240, 2002.

[12] G. Lin, D. Fu, J. Zhu, and G. Dasmalchi, "Cloud computing: IT as a service," IT Professional, vol. 11, no. 2, Article ID 4804041, pp. 10-13, 2009.

[13] C. Vecchiola, S. Pandey, and R. Buyya, "High-performance cloud computing: a view of scientific applications," in Proceedings of the 10th International Symposium on Pervasive Systems, Algorithms, and Networks (I-SPAN '09), pp. 4-16, December 2009.

[14] B. Dit, M. Revelle, M. Gethers, and D. Poshyvanyk, "Feature location in source code: a taxonomy and survey," Journal of software: Evolution and Process, vol. 25, no. 1, pp. 53-95, 2013.

[15] A. Shye, M. Iyer, T. Moseley et al., "Analyis of path profiling information generated with performance monitoring hardware," in Proceedings of the 9th Annual Workshop on Interaction between Compilers and Computer Architectures (INTERACT '05), pp. 34-45, February 2005. 


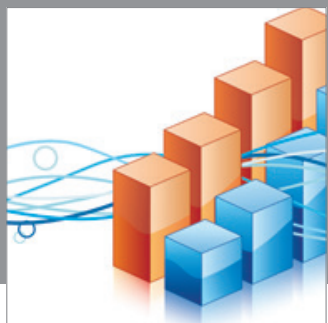

Advances in

Operations Research

mansans

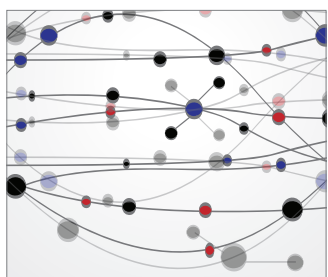

The Scientific World Journal
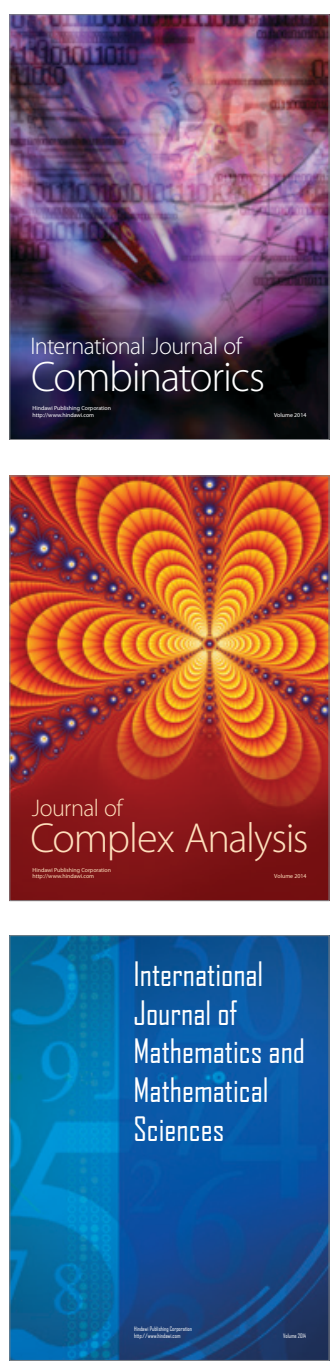
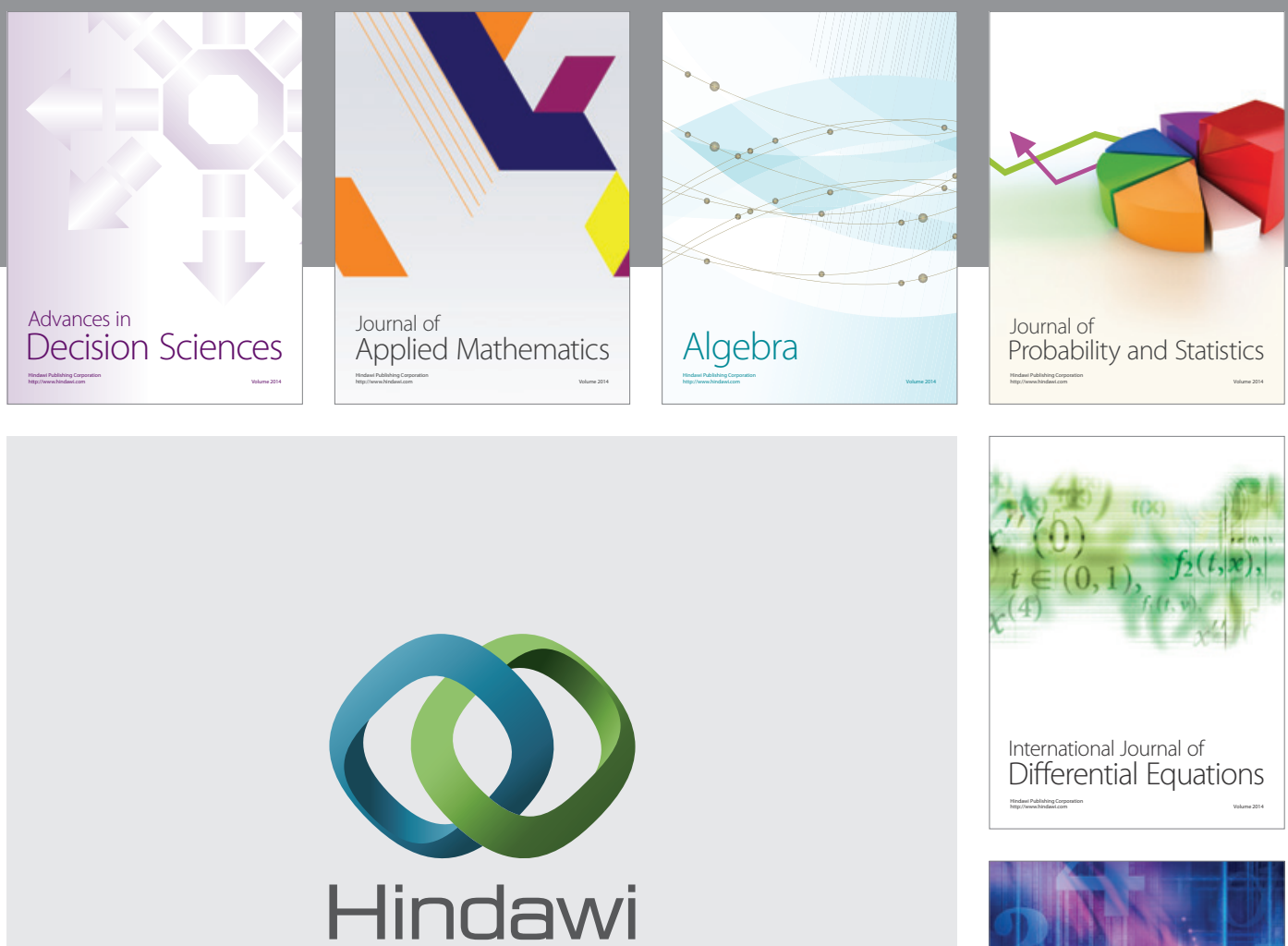

Submit your manuscripts at http://www.hindawi.com
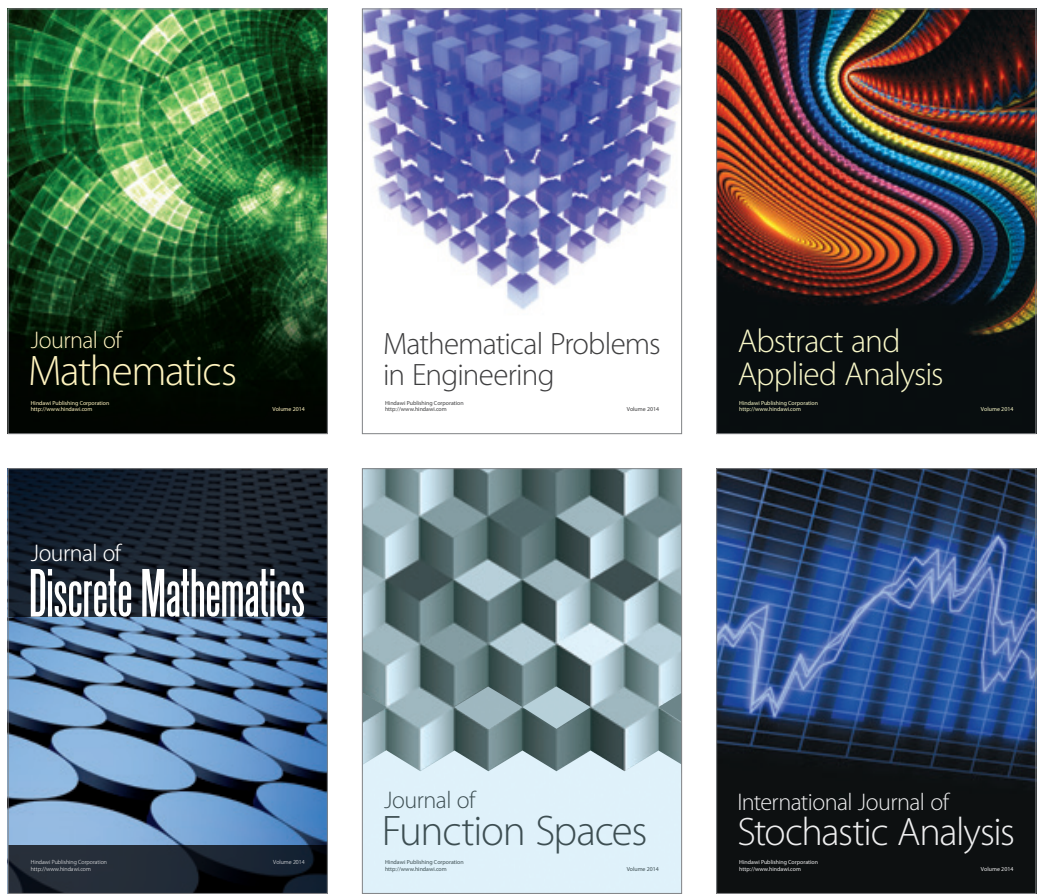

Journal of

Function Spaces

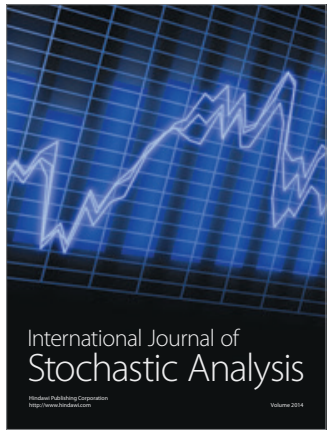

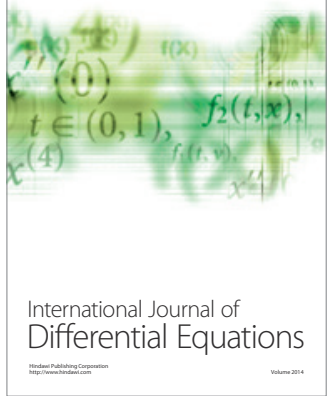
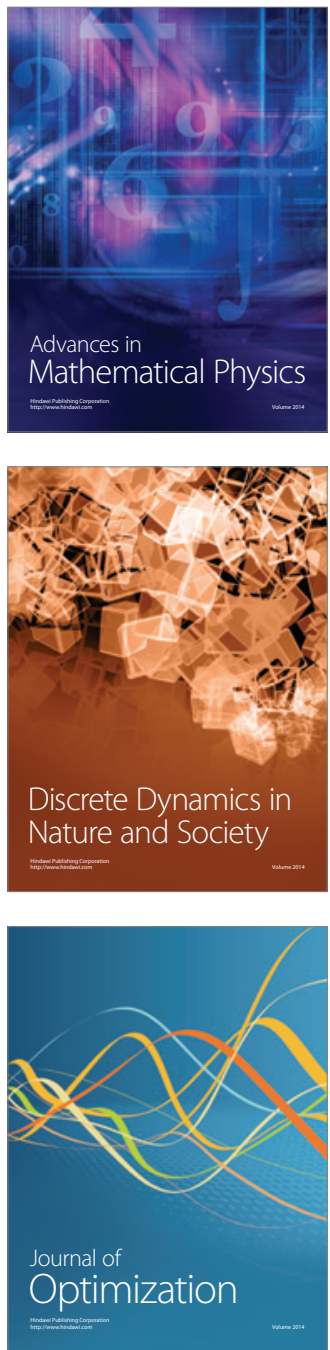